\title{
Characteristics of Homeless Jail Inmates: Implications for Social Work
}

\author{
Everett Jordan Blakely ${ }^{1,2}$
}

This study set out to validate the hypothesis (belief) that homeless people were likely to commit minor offenses as solutions to their conditions. Jails, and maybe prisons, would provide three meals a day, a place to sleep, and minimal health care-especially during the winter months. Instead, the data did not support the hypothesis. Contrany to the reported practices of some homeless people in Colorado who are described as committing non-serious but timed offenses to go to jail, it found a homeless population in jail who give a literal interpretation to the political phrase "the invisible people." They were not in jail because they were homeless, but instead they were in jail for serious crimes (murder, rape, drugs, robbery) and their homelessness was a side fact. Since it was not likely that this group would seek to address or resolve their homelessness, it was recommended that jail social workers identify their needs to them, track them into social welfare networks, with a designated contact person, prior to their release.

KEY WORDS: "invisible people"; crimes; identify needs.

\section{INTRODUCTION}

Homelessness is a societal condition that is being given increasing attention in the political, academic, and human service areas. Correspondingly, there is no doubt that the public is increasingly aware of its existence.

For the most part, studies on homelessness have tended to deal with it as the dependent variable; that is, studies have tended to focus on its

${ }^{1}$ Department of Sociology, The University of Michigan-Flint, Flint, Michigan.

${ }^{2}$ Correspondence should be directed to Everett Jordan Blakely, Department of Sociology, The University of Michigan-Flint, Flint, Michigan 48502-2186. 
pervasiveness and political, economic, social, and psychological causes as well as developing demographic profiles of the homeless population.

This study, in contrast, focuses on homelessness as the independent variable by asking the question of whether homelessness plays a role in criminal activity. Specifically, the study addresses the question of whether or not there is any significant tendency for homeless people to commit deviant acts for the primary purpose of being apprehended and consequently jailed.

Law enforcement authorities generally report that homelessness does not exist among jail inmates, which is technically true due to standard booking procedures which use the last known address at the time of arrest. It was suspected by this writer, as among some other social welfare professionals, that not only are there homeless people in criminal justice systems, but that some homeless people commit certain offenses to "get off the streets," to obtain three meals a day, shelter, and minimum medical care.

It was expected that homeless people who committed crimes to get off the street, committed minor crimes such as loitering, shoplifting, trespassing, vandalism, etc. and did not have the psychological factors that would lead them to commit serious crimes such as homicide, rape, robbery, drugs, and assault simply to end their homeless plight.

\section{METHOD}

The study was conducted in Flint, Michigan which is a midwestern industrial city whose main source of employment has been the auto industry, and where in recent years, the quality of life has dropped drastically from plant closings and layoffs. After obtaining permission from the Under Sheriff of Flint and Genesee County, the arrest records of all arrests in 1988 from January to December were obtained, a total of 8077. The data provided did not contain addresses nor frequency of arrests thereby making it impossible to select a group of homeless inmates for interviews. The data provided did, however, include a computer analysis of age, race, and sex for the total inmate population for 1988 (8077). Since information on crimes for which arrested had not been organized in any way by the computer program, a selection of 500 was made from the 1988 jail population by identifying crimes for which arrested for every twentieth inmate. 
Next, a random sample of 54 current inmates were interviewed during the months of February to April, 1990. Data gathered from those interviews included sex, age, race, crime(s) for which arrested, and whether or not they were homeless. Once interviews were completed, we identified those who were either homeless at time of arrest (using national definition), ${ }^{3}$ had a history of previous homelessness, or were at risk of being homeless. ${ }^{4}$ The interview sample of homeless was then compared to the 1988 total jail population for age, race, and sex, and to the sample of 500 for crimes for which arrested. Significance of the data was determined using the Chi Square test for proportions. In order to assess whether any differences found were linked to homelessness rather than some overall change in inmate population, data from the 27 inmates who were interviewed and found not homeless were also analyzed and included in the comparisons.

The study used the national definition of homeless categories: (1) Long Term-homeless for more than 12 months, (2) Episodic-homeless for less than 12 months due to domestic disputes and living in shelters the end of the month because of a lack of funds, and (3) Transitional-also homeless for less than 12 months but due to evictions or having to pay rent but cannot afford to pay utilities. From the study a fourth category was identified, "At Risk of Being Homeless"-Staying with relatives, friends, girl/boy friend, but do not receive mail at that place of residence.

\section{PURPOSE}

The purpose of the study was to validate the hypothetical premise that: (1) victims of homelessness were in city/county jails, and (2) some homeless victims committed certain crimes as a solution to their homelessness. In other words, homeless victims are victims of gentrification and the government's lack of providing affordable housing, and some are resourceful and some will select "their own means" to end their homelessness, even if it means going to jail.

\footnotetext{
${ }^{3}$ National definition of homeless taken from Michigan's Governor's Task Force on Homelessness (1986). Long term-homeless for more than 12 months. Episodic-homeless less than 12 months. People who live in shelter at end of month due to evictions or no funds. Transitional-homeless less than 12 months. Also live in shelters for first time. May be able to afford rent but not utilities.

${ }^{4}$ This was a category devised during the study. These were inmates who had a place they stayed but did not receive mail at that address. The arrangement was tenuous in that they stayed at an address day-to-day.
} 
Table I. Interview Format

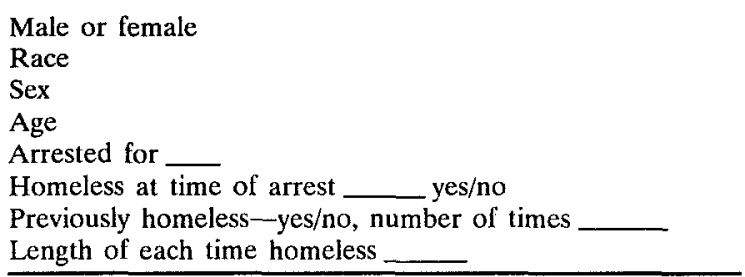

\section{PROCEDURE}

Inmates were interviewed by a research assistant, in the activity areas on both the male and female floors. Total interview time was divided equally between both sexes with each interview taking 10-15 minutes. To preserve confidentiality, inmates interviewed were assigned a code and they were addressed as Sir or Ms. To assure random selection, the interviewer simply approached an inmate, identified herself, stated her purpose, and asked if they would mind being interviewed. The format is shown in Table I. Upon completion, the inmate was thanked for their time.

Inmates on the psychiatric floor were not interviewed since the purpose of this study was not to explore connections between mental illness and homelessness, but to identify that category of homeless victims who use jails as solutions to their condition.

\section{FINDINGS}

The Flint study had several surprises for the research team. While they expected to find homeless people among the inmates, they were surprised at the high number found in the interview sample of 54. From that interview sample of 54 inmates, 27 were identified as homeless at time of arrest, had been previously homeless, or were at risk. The national estimate of homelessness is $1 \%$ of the general population; in a sample of 54 , that would represent less than one person. By including all three categories

Table II. Homelessness Among Jail Inmates, February-April, $1990^{a}$

\begin{tabular}{lcc}
\hline & Number & Sample (\%) \\
\hline Not homeless & 27 & 50 \\
Homeless at time of arrest & 10 & 18.5 \\
Previous homelessness history & 8 & 15 \\
At risk of being homeless & 9 & 16.5 \\
\hline
\end{tabular}

${ }^{a} N=54$. 
Table III. Ten Most Frequent Crimes, Sample from $1988^{a}$

\begin{tabular}{rrrl}
\hline & Code & Number & \multicolumn{1}{c}{ Crime } \\
\hline 1. & 06 & 194 & Operating under the influence \\
2. & 30 & 91 & Drive on revoked license \\
3. & 55 & 52 & Forced entry (res.) \\
4. & 04 & 31 & Cocaine possession \\
5. & 34 & 29 & Assault felonious/aggravated \\
6. & 10 & 27 & Cocaine selling \\
7. & 02 & 26 & Larceny (bldg.) \\
8. & 94 & 26 & Non-payment alimony/child support \\
9. & 45 & 24 & Police officer-strong arm \\
10. & 77 & 23 & Unauthorized use (joy ride) \\
Total & 523 & \\
\hline${ }^{a} N=500$. & &
\end{tabular}

listed in Table II, it was found that $50 \%$ of inmates interviewed were homeless. If we consider only those who were actually homeless at time of arrest $(18.5 \%)$, there is still a significant difference (at better than the .05 level) in percentage of homeless among jail inmates and the national estimates of homelessness. Thus, part 1 of the hypothesis: victims of homelessness were in city/county jails, was supported. After determining the surprising level of homelessness among inmates, analysis of arrest data was done. To the surprise of the research team, the Flint study did not seem to validate part 2 of the hypothesis: some victims of homelessness commit certain minor crimes as a solution to end their homelessness. What it did identify was a group of homeless who were first-time offenders and who were arrested for drug possession (cocaine), cocaine selling, robbery, assault, as-

Table IV. Most Frequent Crimes, Homeless Interview Group ${ }^{a}$

\begin{tabular}{|c|c|c|}
\hline Code & Number & Crime \\
\hline 1. 04 & 7 & Cocaine possession \\
\hline 2. 10 & 4 & Cocaine selling \\
\hline 3. 26 & 4 & Attempted robbery-unarmed \\
\hline 4. 29 & 3 & Selling synthetic narcotics \\
\hline 5. 05 & 3 & Receiving $^{b}$ \\
\hline 6. 17 & 2 & Assault less than murder \\
\hline 7. 07 & 2 & Carrying concealed weapon \\
\hline 8. 51 & 1 & Marijuana-sale \\
\hline 9. 81 & 1 & Loitering $b$ \\
\hline 10. 38 & 1 & Assault-intent to kill \\
\hline 11. 49 & 1 & Sex offense \\
\hline 12. 11 & 1 & Robbery \\
\hline Total & 30 & \\
\hline
\end{tabular}

${ }^{a_{N}}=27$.

${ }^{b}$ Nonviolent and non-drug-related. 
Table V. Most Frequent Crimes, Not Homeless-Interview

Group ${ }^{a}$ February-April, 1990

\begin{tabular}{|c|c|c|}
\hline Code & Number & Crime \\
\hline 1. 04 & 7 & Possession of cocaine \\
\hline 2. 29 & 4 & Selling synthetic narcotics \\
\hline 3. 26 & 3 & Attempted robbery-unarmed \\
\hline 4. 10 & 2 & Selling cocaine \\
\hline 5. 18 & 2 & Prostitution $^{b}$ \\
\hline 6. 11 & 2 & Robbery \\
\hline 7. 07 & 2 & Carrying concealed weapon \\
\hline 8. 01 & 2 & Homicide \\
\hline 9. 17 & 2 & Assault less than murder \\
\hline 10. 51 & 1 & Marijuana-sale \\
\hline 11. 53 & 1 & Commercial sex ${ }^{b}$ \\
\hline 12. 24 & 1 & Forced entry-non resident \\
\hline 13. 45 & 1 & Police officer - strong arm \\
\hline 14. 06 & 1 & Operating under influence ${ }^{b}$ \\
\hline 15. 41 & 1 & Fugitive $^{b}$ \\
\hline 16. 49 & 1 & Sex offense \\
\hline 17. 21 & 1 & Kidnap-adult \\
\hline 18. 71 & 1 & Other non-hazardous violation ${ }^{b}$ \\
\hline Total & 35 & \\
\hline
\end{tabular}

${ }^{a}$ February-April, 1990; $N=27$.

${ }^{b}$ Nonviolent/drug-related.

sault with intent to kill, and other major serious crimes. These are the same types of crimes that the "antisocial type" would commit. These people would be socially perceived as a criminal element instead of homeless persons.

Table III shows the most frequent crimes from the 1988 sample. They are generally non-serious, non-drug related crimes. However, operating under the influence (194) could be viewed as posing a serious threat to society.

Tables IV and V show the 54 who were interviewed in 1990 to have a higher rate of violent and drug-related crimes (84.5\%) than the 1988 sample.

Even after adding the number of arrests for operating under the influence (Code 06) for 1988, which increased the percentage of arrests for violent and drug-related crimes to $58 \%$, and doing a correction for continuity, the data still showed an increase in arrests for violent and drug-related crimes from 1988 to 1990 that was significant at better than the .05 level.

We then compared the percentage of arrests for violent and drug-related arrests within the 1990 interview sample. We found that the homeless had an arrest rate for violent and drug-related crimes of $87 \%$, and the non-homeless had a rate of $82 \%$. While this represents a higher rate of 
Table VI. Comparison of Homeless Jail Inmates to Non-homeless and Total Inmate Population

\begin{tabular}{|c|c|c|c|c|c|c|}
\hline Comparison data & \multicolumn{2}{|c|}{$\begin{array}{c}\text { Total inmate } \\
\text { population, } \\
1988(N=8077)\end{array}$} & \multicolumn{2}{|c|}{$\begin{array}{c}\text { Homeless } \\
\text { inmates, } \\
\text { Feb-April } \\
1990(N=27)\end{array}$} & \multicolumn{2}{|c|}{$\begin{array}{c}\text { Non-homeless } \\
\text { inmates, } \\
1990(N=27)\end{array}$} \\
\hline Average age & \multicolumn{2}{|c|}{32} & \multicolumn{2}{|r|}{23} & \multicolumn{2}{|c|}{28.5} \\
\hline Male & 7257 & $(90 \%)$ & 23 & $(85 \%)$ & 18 & $(66 \%)$ \\
\hline Female & 822 & $(10 \%)$ & 4 & $(15 \%)$ & 8 & $(33 \%)$ \\
\hline \multicolumn{7}{|l|}{ Racial group } \\
\hline Black & 3601 & $(44 \%)$ & 20 & $(74 \%)$ & 18 & $(66 \%)$ \\
\hline White & 4326 & $(53 \%)$ & 7 & $(26 \%)$ & 8 & $(30 \%)$ \\
\hline Hispanic & 135 & $(2 \%)$ & 0 & & 1 & $(3 \%)$ \\
\hline Other & 15 & $(1 \%)$ & 0 & & 0 & \\
\hline
\end{tabular}

arrests for violent and drug-related crimes for homeless inmates, this difference could have resulted from sample error.

The data presented three important questions to the researchers: (1) how to explain the significant increase in the number of inmates in the County Jail who were arrested for violent and drug-related crimes, (2) how to explain the finding that those inmates who were homeless had an arrest rate for violent and drug-related crime that was at least similar to if not higher than the rate for non-homeless, and (3) how to explain the significant difference between percentage of homeless among jail inmates and that of general population (estimated at $1 \%$ by national estimates).

These questions could not be clearly answered by the data gathered in the research, nor easily answered by County Jail data currently available. However, some tentative and likely explanations do exist.

It is known that Flint, along with other major cities in Michigan has experienced a serious increase in jail overcrowding. It is very likely that the increase in overall rate of inmates who were arrested for violent and drug-related crimes reflects a growing necessity to keep in jail only those arrested for more serious crimes. Therefore, those arrested for less serious crimes (those the researchers expected to find committed by homeless) are not likely to be kept in jail.

Further comparison of those interviewed inmates with the data from the 1988 inmate population is shown in Table VI. Table VI shows more females in jail in $1990(15 \%)$ than in $1988(10 \%)$, but there are more males among the homeless $(85 \%)$. It shows the homeless are younger in age (23) than the total jail population in 1988 and also younger than the nonhomeless. And it shows they are younger than HUD's estimates of average age 
for homeless people as mid-thirties. Blacks are more likely to be homeless in that they comprised $74 \%$ of the homeless group, but only $66 \%$ of the nonhomeless group. Blacks comprised only $44 \%$ of the total jail population in 1988.

And finally, the Flint Study showed that Blacks who are homeless committed more violent and drug-related crimes than the total jail population.

\section{ANALYSIS AND CONCLUSION}

Flint, Michigan has been described as a microcosm of the general society in that it reflects most of the same social problems that are national issues: high unemployment, the impact of plant closings and layoffs on a community (LINK, 1990), ${ }^{5}$ what can happen when the average citizen is unskilled and has less than a high school education, what can happen when the dropout rate among high school adolescents is $46 \%$ of the city's youth and those youths have no value orientation toward being self-sufficient (Facilities Utilization Task Force Report, 1987, pp. 29, 32-33). However, Flint appears to differ from other communities its size in how homeless people solve their plight. For example, a Correctional Specialist in the Colorado Correctional System reported a pattern among "street people" in Colorado. Eighty percent of their crimes were nonviolent, i.e., theft, auto theft, burglary, etc., and $65 \%$ were over the age 35 but under age 50 . Their crimes were committed in the summer to late fall whereby they would be sentenced before and during winter months. In the Flint Study, those arrested and homeless individuals were arrested for major crimes. Their homelessness was a later discovered fact. The question could be posed that in Michigan, where jail overcrowding is a major and growing problem, who goes to jail and who stays in jail is considered differently than in Colorado systems.

The Flint Study indicated that "the appearance of success is still the norm." When the auto industry was thriving prior to the layoffs and cutbacks, to work in "the factory" meant one had arrived, had it made. A person could be unskilled with no high school education and make a yearly salary of $\$ 50,000-\$ 60,000$ and could reflect a lifestyle of affluence. Now youth in their late teens and early twenties who are members of the drug culture drive Mercedes Benz, Trackers (a four wheel drive jeep type vehicle), wear top line Reeboks and Nikes: all to continue the appearance of success. The need to appear successful is a strong socialized value among

${ }^{5}$ Between 1984-1988, Genesee County lost 16,700 automotive and related jobs, with 900 scheduled to be terminated in 1991. In 1987, Flint alone lost 8600 jobs. 
many families in Flint (Facilities Utilization Task Force Report, 1987, pp. 28-29). This value is so strong that one can be desensitized to the reality of being homeless but very sensitive to being insulted, disrespected, or territorially threatened and respond with acts such as assault with intent to kill and felonious assaults.

The Flint Study showed a high percentage of inmates who lived with relatives (cousins) and girlfriends: the At-Risk Group. When this occurrence was clarified, it was revealed that these were individuals who dealt in drugs, using, and/or selling. They stayed with relatives or girlfriends because they had been put out of their primary homes by parents and/or could not find meaningful work or stay consistently employed, so they dealt drugs as a source of income.

When the interviewer wondered to an inmate if he was concerned about not having any place to stay (homeless) his response raised an interesting point: "When you are dealing to make money, you have to be mobile, moving, not tied down." "You have to be out there in the streets to sell, at any time, all the time." "It goes with the territory." Another inmate, homeless at the time of his arrest stated, "I'm too busy making money to worry about where I sleep. I eat wherever I find some to shack up with for the night. I either buy her for the night or simply give her some dope. When you got money and drugs, you don't worry about where you are going to stay ...." On further analysis it can be a way to protect one's self by making it difficult for the authorities to locate you and difficult for violence-prone individuals who also "deal" to track you.

\section{IMPLICATIONS}

Studies, at times, have the purpose of developing services or supporting existing services. In the Flint Study, the homeless jail population is not likely to benefit from current McKinney-based services or have traditional homeless services developed for them because they would not likely seek such services or use them if offered (Michigan Governor's Task Force on Homelessness, 1986). ${ }^{6}$ Their homelessness is a side fact, not an issue to them. Also, city and county jail systems would not identify them because their crime is the focus.

So the official reply "There are no homeless people in jail." is technically correct. For these inmates they "are not homeless," they got caught. It could be philosophically stated that these homeless inmates are a "so-

${ }^{6}$ Programs whose existence or funding source comes from the McKinney Act, legislation, and monies specifically designed for the homeless. 
cially lost group." If they are not concerned about being homeless, recent developing societal attitudes are not going to be those of concern.

A further implication of the Flint study has to do with those homeless who, in the past, may have used jail as a solution to their homelessness, and who now, due to the overcrowding problems of Michigan's jails, are unable to utilize this solution. One must wonder where they are and whether sufficient solutions exist for them.

Social work services for those homeless found among jail inmates will likely need to be creative, nontraditional, and assertive in that this group will need to have their needs identified to them by a competent, sensitive, and culturally aware social work professional. Since it is not likely that this group will seek needed services upon their release it is suggested they be assessed for their other needs during their incarceration and the appropriate social work services be started while they are incarcerated.

In order to consider development of appropriate social work services for those homeless who were found to be in jail, as well as address the other questions raised in this study, it is suggested that replication of this study needs to be done, both in Flint and in other major cities. In addition, new research is indicated in order to further explore the connection between drug problems and homelessness.

\section{ACKNOWLEDGMENT}

This paper was edited by Wanda Wolosuk, M.S.W., Faculty, Saginaw Valley State University.

\section{REFERENCES}

Anderson, Baker, \& Snow (1984/85). Criminality and homeless men: An empirical assessment. Social Problems, 36(5).

Blakely, E. J., \& White, R. Transitional housing issues: Domestic violence and the homeless. P.U.R.A. 1988, The University of Michigan-Flint: Flint, Michigan.

Burt, C. (1989). Differences among homeless single women, single men and women with children. Social Problems, 36(5).

Ellickson, R. (1990). The homeless muddle. The Public Interest, 99.

Facilities Utilization Task Force Report (1987). A Study Conducted by the Flint School Board to Assess the Feasibility of School Consolidation.

Finn, P. (1988). Street people. National Institute of Justice, U.S. Department of Justice.

First, R., Ruth, D., \& Arewa, B. (1988). Homelessness: Understanding the dimensions of the problem for minorities. Social Work Journal, 33.

Flannagan, W. G. (1990). Urban sociology: Images and structures. Boston, Massachusetts: Allyn and Bacon.

Flint/Genesee County Comprehensive Homeless Assistance Plan. Flint, Michigan: Department of Community Development. 
LINK (1990). $I V(3)$. Project for urban and regional affairs. A Study Conducted by the Michigan Employment Security Commission, University of Michigan-Flint, Flint, Michigan.

Michigan Governor's Task Force on Homelessness (March 1986). Life in transit. New Dimensions (Feb. 1990). Homelessness: Fact vs. Lies.

Robertson, J. (May 1988). Homeless adolescents: A hidden crisis. Journal of Hospital and Community Psychiatry, 39(5).

Wilkinson, K. (Dec. 1987). Dropout prevention in the elementary school years. Project for Regional and Urban Affairs, University of Michigan-Flint, Flint, Michigan.

Wisconsin: The Institute for Research on Poverty. Tracking the Homeless. The University of Wisconsin, Madison. 